\title{
Tarefas propostas para a utilização do material adaptado "Régua de frações" para o ensino de frações a cegos
}

\author{
Proposed tasks for the use of the adapted material "Ruler of fractions" for the \\ teaching of fractions to the blind
}

\author{
Natali Angela Felipe ${ }^{1}$ \\ Maria Ivete Basniak ${ }^{2}$
}

\section{Resumo}

Objetiva-se com este artigo contribuir para o ensino de frações a cegos, mediante a discussão de tarefas propostas para a utilização de material adaptado. Originou-se da dificuldade de encontrar materiais adequados para este ensino durante o trabalho realizado no Projeto Institucional de Bolsa de Iniciação à Docência- PIBID em atuação na Sala Multifuncional Tipo II. Neste sentido levando em consideração a organização, manuseio e significação tátil do aluno, o material apresentado compõe uma caixa com divisórias e um tabuleiro, onde peças de madeira divididas em partes iguais são manipuladas e identificadas por indicações em Braille de suas respectivas frações. Para a sua utilização são apresentadas tarefas com encaminhamentos objetivando o ensino do conceito de fração, comparação, equivalência e as operações de adição e subtração de frações, bem como, baseado na sua aplicação são apresentadas limitações e possíveis adlaptações frente a funcionalidade do material e as tarefas propostas, as quais utilizam a percepção tátil e a oralidade para promover a generalização do conceito de fração e suas operações.

Palavras- chaves: Ensino de frações. Material adaptado. Cegos. Matemática.

\section{Abstract}

The objective of this article is to contribute to the teaching of fractions to the blind, through the discussion of proposed tasks for the use of adapted material. It originated from the difficulty of finding suitable materials for this teaching during the work carried out in the Institutional Project of the teaching initiation scholarship - PIBID, in action the Multifunctional Room Type II. In this sense, considering the student's organization, handling and tactile significance, the presented material composes a box with partitions and a tray, where pieces of wood divided into equal parts are manipulated and identified by Braille indications of their respective fractions. For its use, tasks with forwarding are presented, aiming at teaching the concept of fraction, comparison, equivalence and operations of addition and subtraction of fractions, as well as, based on its application, limitations and possible adaptations are presented regarding the functionality of the

\footnotetext{
${ }^{1}$ Mestranda em Ensino de Ciências e Tecnologia (UTFPR), Professora Colaboradora no colegiado de Matemática, Universidade Estadual do Paraná- UNESPAR campus de União da Vitória, natthali_felipe@hotmail.com.

2 Doutorado em Educação (UFPR), Professora no colegiado de Matemática, Universidade Estadual do Paraná- UNESPAR campus de União da Vitória, basniak2000@yahoo.com.br.
} 
material and the proposed tasks, which use tactile perception and orality to promote the generalization of the concept of fraction and its operations.

Keywords: Teaching of fraction concepts. Adapted material. Blind. Mathematics.

\section{Introdução}

Embora se presencie discussões relacionadas à inclusão de alunos com necessidades especiais nas escolas regulares, observa-se que a busca por adaptações e alternativas metodológicas só surgem quando a escola recebe um aluno com necessidades especiais. Como essa inserção ainda é recente e mobiliza desde a década de noventa discussões sobre práticas educativas e inclusivas, percebe-se a necessidade de adaptar, criar, refletir e divulgar alternativas de ensino e materiais para possibilitar o acesso destes alunos ao conhecimento.

O ensino para pessoas com cegueira total comumente envolve práticas didáticas e adaptações que usam o tato e a oralidade como pontes de acesso e promoção de conhecimento, "[...] já que é o corpo - especialmente a percepção tátil - que proporciona acesso ao mundo que os circunda ao mesmo tempo em que limita o campo perceptivo. Só faz parte do campo perceptivo do cego o que é tangível ao seu corpo" (FERNANDES E HEALY, 2011, p. 141). Nesse sentido, tratando-se do ensino de Matemática a cegos acredita-se que as adaptações e práticas pedagógicas devem possibilitar ao aluno cego ter acesso e a percepção dos conteúdos matemáticos por meio do tato (materiais manipuláveis), e naturalmente pela oralidade.

Estas percepções acerca da Educação Inclusiva e também do Ensino de Matemática para cegos deram-se durante a atuação da primeira autora deste trabalho em uma escola da rede pública de ensino em Sala Multifuncional Tipo II, por meio do Programa Institucional de Bolsa de Iniciação à Docência- PIBID. Dessa forma, o material adaptado da Régua de Frações aqui apresentado, é 
oriundo do seu trabalho de conclusão de curso ${ }^{3}$, que objetivou discutir o ensino e aprendizagem de frações a cegos, mediante análise da aplicação de uma proposta de ensino utilizando material adaptado. Destaca-se assim, que o objetivo desse artigo é discutir tarefas propostas para a utilização do material adaptado para o ensino do conceito de fração, comparação, equivalência e as operações de adição e subtração de frações.

Para a discussão na seção que segue apresentamos brevemente alguns conceitos de frações referindo possibilidades no ensino para cegos. Em seguida, na seção 3, apresentamos as características do material adaptado, enquanto que na seção 4 são apresentadas propostas de tarefas e encaminhamentos para o uso no ensino de frações a cegos do material adaptado. Na seção 5 são apresentados apontamentos referentes às limitações e possíveis adaptações, tanto do material, quanto dos encaminhamentos da aplicação do material, seguidos das considerações finais do trabalho.

\section{0 ensino e os conceitos de frações}

Ao que se refere ao ensino de frações, ao analisar os principais documentos norteadores da estrutura curricular como os Parâmetros Curriculares Nacionais de Matemática- PCN (1997) e as Diretrizes Curriculares da Educação Básica do Estado do Paraná de Matemática (2008) nota-se que o estudo dos números fracionários é contemplado como um conteúdo dentro dos conjuntos dos números racionais.

$\mathrm{Na}$ Diretriz Curricular da Educação Básica do Estado do Paraná de Matemática (2008), o conteúdo de frações é abordado por meio do conteúdo estruturante de Números e Álgebra no sexto ano, mas com o objetivo de

\footnotetext{
${ }^{3} \mathrm{O}$ trabalho de conclusão de curso desenvolvido em 2014 para obtenção do grau de Licenciatura em Matemática é intitulado "Ensino de frações a deficientes visuais utilizando material adaptado" e encontra-se disponível em: http://matematicafafiuv.pbworks.com/w/file/fetch/88695437/ENSINO\%20DE\%20FRA\%C3\%87\%C3 \%95ES\%20A\%20DEFICIENTES\%20VISUAIS\%20UTILIZANDO\%20MATERIAL\%20ADAPTADO.p df.
} 
estabelecer a relação de igualdade e transformação entre: fração e número decimal; fração e número misto, ou seja, não especificando como deve ser contemplado o ensino de conceitos e operações com números fracionários. Já segundo os PCN (1997) os números racionais devem ser trabalhados já no segundo ciclo (quarto e quinto ano) contemplando o ensino de frações com os significados de parte-todo, quociente, razão e como operador.

Segundo os autores Nunes e Bryant (1997, apud SILVA, 2006), é comum a apresentação de frações às crianças como todo dividido em partes, tal que algumas são pintadas, ainda recebendo a informação de que a quantidade de partes pintadas corresponde ao numerador da fração e o total de partes que 0 todo é dividido ao denominador. Ainda sobre a primeira ideia de fração que a criança recebe, Lima e Brito (2001, apud SILVA, 2006) afirmam que o primeiro conceito de fração elaborado é como sendo um "pedacinho" de um todo, ou ainda como algo menor que o todo.

Assim, Silva (1997) aponta as apresentações das figuras já divididas como não garantia do aprendizado do conceito de fração, pois as divisões não são feitas pelos alunos. E trata esta situação como um modelo estático, no qual o aluno não exerce ação na situação apresentada. Descreve ainda, que devido a estas divisões preestabelecidas o aluno tem tendência a usar o procedimento de dupla contagem ${ }^{4}$ em modelos contínuos.

Nunes e Bryant (1997, apud MALASPINA, 2007) mencionam a preocupação de Campos (1995) quando crianças são submetidas a somente um método de ensino que as estimulam a resolverem problemas utilizando o procedimento de dupla contagem (contagem das partes do todo e da divisão em partes iguais), restringindo o conceito do número fracionário. Os autores defendem que estes procedimentos de contagem remetem características dos

\footnotetext{
4 Os autores Silva (1997), Nunes e Bryant (1997, apud MALASPINA, 2007) entendem o procedimento de dupla contagem, como a contagem de parte pintadas, consideradas ou tomadas (numerador) e a contagem das partes em que o todo é dividido (denominador), ou seja, a fração para o aluno se reduz a contar as partes e então organizá-las na representação de fração. Dessa forma compreendem a fração como a divisão de dois números naturais e não como um "novo número" o número fracionário.
} 
números naturais às crianças, devido a contar partes, não desenvolvendo a noção de que as frações são outro tipo de número. Em decorrência disto apontam que isso pode acarretar problemas futuros, como erros em comparações e em operações com números fracionários.

Ao encontro de Silva (1997), Llinares (2003, apud VASCONCELOS, 2007) e Mack (1990, apud MALASPINA, 2007) sugerem a relação parte/todo ou a partição como um ponto de partida para a compreensão das frações. $O$ ato de dividir em partes equivalentes ajuda a desenvolver representações internas das noções sobre frações, possibilitando conhecimentos intuitivos de frações sem a necessidade de ligações com símbolos matemáticos.

Para a introdução do conceito de fração, utilizando a concepção de medida, Polese (2011) propõem que os alunos dividam tiras de cartolinas em partes iguais. Essa atividade vai ao encontro da concepção de Silva (1997) sobre o ensino de frações mencionado anteriormente, com o aluno exercendo o "ato" de dividir ou fracionar algo em uma situação posta pelo professor.

Quanto à comparação de frações, Bryant (1994, apud MACHADO, 2007) sugere que a partir do significado parte/todo, ao dividir o todo em partes, poderiam ser desenvolvidos os primeiros conhecimentos lógicos referentes à quantificação de frações, podendo julgar partes do todo como maiores, menores ou iguais à outra. Uma estratégia que poderia evitar ou amenizar um dos obstáculos citados nos PCNs (1997) sobre as comparações de frações, pois os alunos estão acostumados com a relação $3>2$, e tem que construir uma escrita e um conceito que Ihes parece contraditório num primeiro momento, quando comparam, por exemplo, $\frac{1}{3}<\frac{1}{2}$.

Concomitante a ideia de Bryant e utilizando da ideia de tiras recortadas em partes iguais, Morais (2012) constrói uma régua de frações e a utiliza para comparar uma parte de quatro e três partes de quatro em que o aluno representa pictoriamente as frações da régua usada pela professora e as compara observando seu registro. 
Para realizar comparações entre números fracionários e realizar operações entre eles pode-se utilizar o conceito de equivalência entre frações, porém Merlini (2005) aponta que a dificuldade em compreender a equivalência de frações está em entender que cada fração pode ser representada por diferentes e infinitas outras frações.

Nunes e Bryant (1997, apud COSTA, 2011) acreditam que o ensino de frações na perspectiva parte/todo, priorizando representações de todos e partes pintadas desenvolve o raciocínio das frações por meio de percepções.

Nesse sentido Silva (2007) enfatiza que as propostas envolvendo o significado parte/todo são importantes para a compreensão da equivalência de frações. Talvez uma evidência permitida pelas representações de parte/todo que possibilitam por meio de registros, desenhos e figuras a percepção de mesmas representações de partes do todo, sem a necessidade de utilização do m.m.c (mínimo múltiplo comum) e nem de regras operatórias para adicionar ou subtrair frações conforme atividades descritas por Pelissaro (2011).

Dentro dos materiais que podem ser utilizados como recurso didático para o ensino e aprendizagem a cegos está o Soroban, um recurso educativo específico para execução de cálculos matemáticos por alunos com cegueira ou baixa visão grave. Seu uso está previsto em lei e assegurado pela Portaria MEC no 1.010, de 10 de maio de 2006 (BRASIL, 2006) e geralmente é descrito em manuais, com procedimentos para a realização de operações apresentadas como "regras" ou "passo a passo" de registros, pois todos os cálculos são realizados mentalmente.

Obviamente todas as regras são fundamentadas pela lógica matemática, justificando os registros, porém estas geralmente não são discutidas quando se objetiva ensinar a operar frações no Soroban. No ato de aprender a realizar os registros e executar os cálculos, a técnica acaba se sobressaindo ao conceito matemático. Desta forma, apresenta-se a seguir o material adaptado e uma proposta de ensino de frações para cegos, a qual utiliza a percepção tátil da manipulação do material e a oralidade (questionamentos e respostas) para a 
construção e elaboração de generalizações dos conceitos de frações e suas operações.

\section{O material adaptado}

A adaptação do material para o ensino de frações foi pensada a partir da reflexão sobre a aplicação de um plano de aula sobre frações para uma aluna com deficiência visual em Sala Multifuncional Tipo II, com o material "frações no pote". Adaptou-se então, o material "régua de frações", composto de peças que possuem representações de frações em madeira, utilizaram-se assim suas peças divididas em até 11 partes iguais e acrescentando peças com 12 divisões em partes iguais (as quais foram confeccionadas). Nas peças foi incluído o símbolo em Braille correspondente a fração representada pela peça, para a familiarização com os símbolos.

Por questões de mobilidade, manuseio e organização espacial, foi adaptada uma caixa para o uso destas peças que permite separá-las em 10 divisórias de diferentes tamanhos na parte detrás da caixa. Para facilitar sua localização e a limitação de espaço o aluno pode posicionar todas as peças em estudo na parte da frente da caixa (que será identificada nos encaminhamentos neste trabalho como tabuleiro), evitando a mistura e perda das mesmas durante as tarefas.

Pela caixa ser limitada nos lados e atrás (antes das divisórias), a parte da frente da caixa pode ser removida possibilitando ao aluno movimentar as peças dentro do tabuleiro sem ficar com os punhos levantados (posição desconfortável). $\mathrm{Na}$ figura 1 pode ser observado o material adaptado e na figura 2 as possibilidades de disposições das peças, tal que durante todos os encaminhamentos deste trabalho se fará referência a peças sobrepostas, peças lado a lado, peças lado a lado em mesma fileira e peças em mesma fileira. 


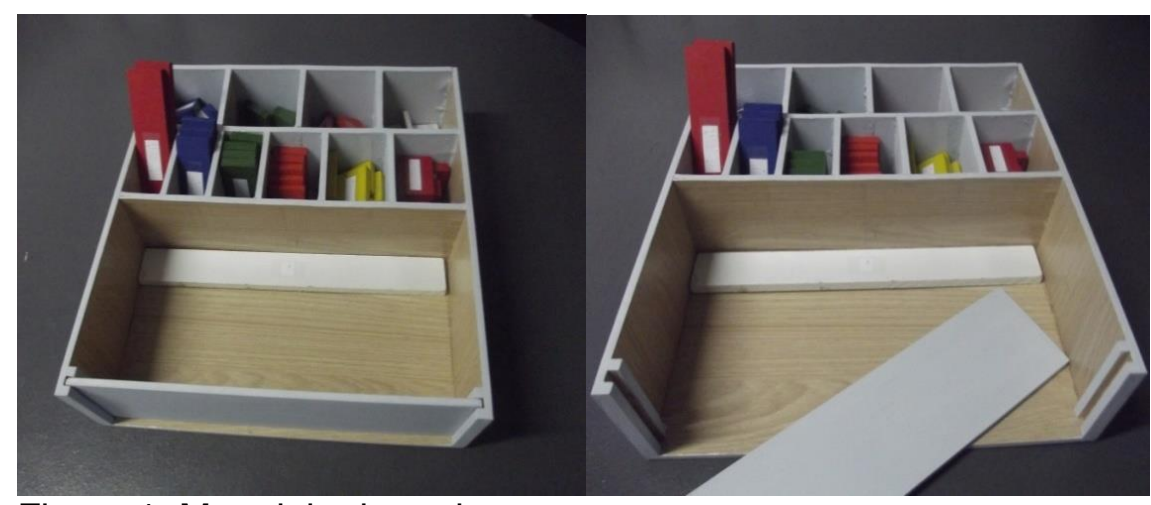

Figura 1: Material adaptado.

Fonte: Autoras, 2014.

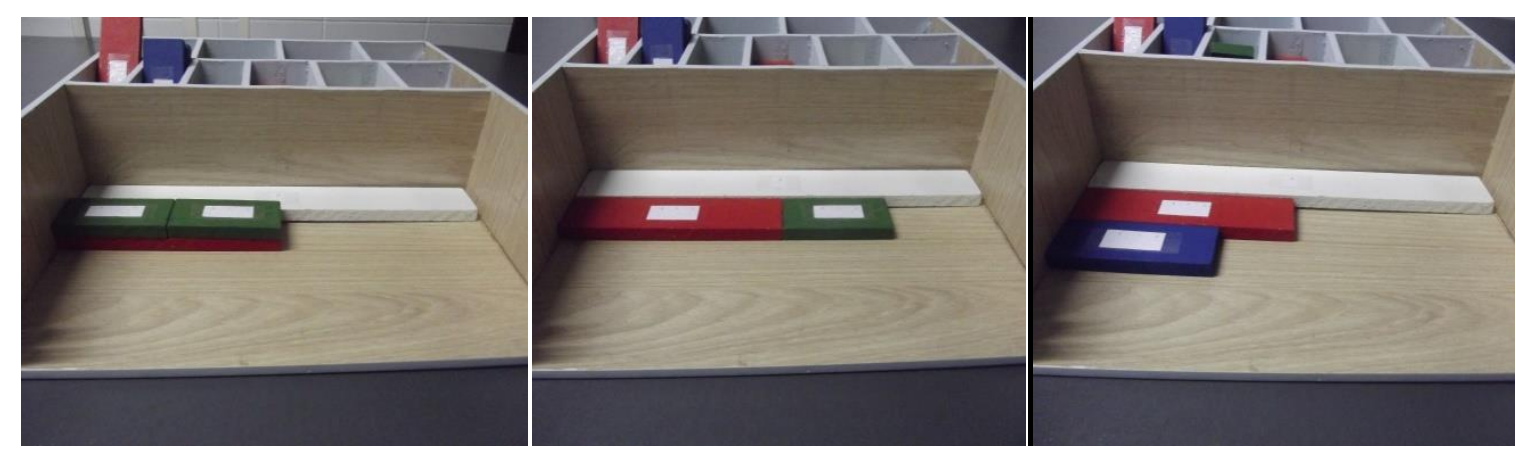

Figura 2: Disposição das peças sobrepostas, lado a lado em mesma fileira e lado a lado.

Fonte: Autoras, 2014.

Uma sugestão de organização das peças nas divisórias é colocar as maiores na frente e as menores atrás, pois as divisórias foram construídas de forma que as detrás são maiores, cabendo a mão, facilitando a retirada de peças pequenas dessas divisórias. Assim o professor deve orientar o aluno a sempre colocar a peça que representa o todo no tabuleiro (usada como referência), na primeira divisória as peças que correspondem a duas divisões e assim sucessivamente até as peças que são divididas em 12 partes iguais, lembrando que as peças de 11 divisões não pertencem ao material.

Esta organização (ou a escolhida) deve ser mantida para todas as tarefas a serem propostas durante o trabalho com o material, com o intuito do aluno adquirir habilidade e autonomia ao manusear as peças do material. 


\section{Ensino de frações a cegos: propondo tarefas e encaminhamento para o uso do material adaptado}

As tarefas e encaminhamentos propostos estão ancoradas em Silva (1997), Polese (2011), Morais (2012), Silva (2007) e Pelissaro (2011) e buscam possibilitar ao aluno cego construir o conceito de frações partindo da concepção de medida (LIMA; BRITO, 2011, apud SILVA, 2006). E a partir desse conceito, realizar comparações entre frações no material, além de compreender e encontrar frações equivalentes, e então adicioná-las e subtraí-las.

Uma forma intuitiva de se explicar e propiciar o desenvolvimento do conceito de número fracionário de forma similar a proposta para os alunos visuais usando a concepção de Silva (1997) é por meio da divisão de um todo em partes iguais e não simplesmente "tomar" (contar) partes do todo já dividido, similar à ideia de dividir tiras de cartolina (proposta de Polese (2011) discutida dentro do ensino de frações). Porém, pelo comprometimento visual do cego, medir, desenhar, pintar e cortar tornam-se tarefas difíceis de serem aplicadas, já dobrar em partes iguais ou manipular peças torna-se algo possível, podendo essas peças representarem o todo e também diferentes divisões em partes iguais.

É normal então devido à representação utilizada no Braille que o aluno cego associe o número fracionário com uma divisão, visto que a representação do traço de fração assumida no trabalho tem simbologia igual à de "barra" : Naturalmente está é associada também com resultado em número decimal, assim a explicação de que esta representação se refere a um "novo" número, os números fracionários, poderá ser discutida e mais, o aluno deverá ser capaz de entender que há duas possibilidades para a mesma representação fracionária, o que pode ser confuso em um primeiro momento.

Quanto à comparação de frações acredita-se, baseado em Morais (2012), que quando se analisa a representação por figuras ou pelo tamanho das peças, o que será possibilitado pelo material, o choque conflitante com a comparação dos 
naturais com as frações não se torna tão evidente. Visto que a partir de toda a construção que pode ser realizada por meio do aluno dividir ou perceber as divisões em partes iguais, pode dar mais ênfase a percepção de que, quanto mais divisões realizar, peças ou retângulos (partes) menores serão obtidos.

Uma das dificuldades dos alunos pode ser a de compreender que cada fração pode ser representada por outras frações, que são equivalentes, ou seja, representam a mesma parte do todo. Por que não desenvolver mais facilmente esta percepção por meio da manipulação de peças que evidenciem esta equivalência? Baseando-se em Pelissaro (2011) compreendemos que a equivalência de frações poderá auxiliar na realização das operações de adição e subtração, pois é por meio deste princípio que o aluno poderá ter menor dificuldade em realizar estes cálculos e utilizar a equivalência para substituir o cálculo do m.m.c para operar frações, dando ênfase ao conceito e a generalização e não a procedimentos.

As tarefas propostas são estruturadas com questionamentos básicos para atingir os objetivos descritos nas mesmas, ou seja, estão baseadas no ensino por meio de indagação, investigação e da oralidade frente às manipulações táteis realizadas no material. Isso não significa que não serão necessários outros questionamentos ou adaptações no decorrer da aplicação, para suprir a não compreensão e a necessidade de aplicação de mais exemplos para generalizações e a sistematização do conceito e das operações de frações.

A proposta não traz conceitos e definições pré-estabelecidas para serem apresentadas aos alunos, destaca-se além dos objetivos da tarefa, possibilidades de discussões e apresentações de definições, mas deixa-se a cargo do professor a busca por conceitos formais, como também a escolha por aplicação de outros exemplos para explorar mais cada conceito sobre frações.

\subsection{Construindo o conceito de fração}


Esta primeira tarefa tem como objetivo que 0 aluno entenda que as frações pertencem a um novo campo numérico e, portanto, expressam quantidades relacionadas a medidas, sendo referência o todo dividido em partes iguais do qual se toma uma ou mais de suas partes. Assim, espera-se que o aluno realize a divisão de tiras de cartolina em duas partes iguais por meio de dobras e que a partir do tato e pelo vinco deixado pela dobra, perceba a divisão ao meio (na metade) e que intuitivamente responda que cada parte representa meia tira.

E da mesma forma, que ao dobrar a tira em quatro partes iguais perceba que cada parte dobrada é uma parte do todo dividido (dobrado) em quatro partes iguais, ou seja, um quarto da tira. E que infira que divisões em partes iguais na tira de cartolina podem ser feitas várias vezes (dividindo continuamente), sendo que quanto mais divisões forem feitas na tira de cartolina menores serão as partes obtidas por estas divisões.

Assim, para esta primeira tarefa o professor deve fornecer uma tira de cartolina com medidas de $32 \mathrm{~cm}$ por $3,5 \mathrm{~cm}$ ao aluno (para que posteriormente faça relação com as peças do material adaptado na tarefa 2) e organizar sua carteira (ou mesa) para que somente se encontre nesta a tira de cartolina fornecida, para mais facilmente dobrá-la devido a falta de refinamento em seus movimentos.

Em seguida o professor orientará o aluno para dobrar a tira em duas e em seguida em quatro partes iguais, perguntando: E agora como ficou dividida a tira? Quanto cada parte representa da tira de cartolina? É possível realizar outras dobras na cartolina de forma que os vincos deixados a dividam em partes iguais? Você poderia dividi-la novamente em partes iguais? E novamente? Quantas vezes mais você poderia dobrar a tira de cartolina buscando dividi-la sempre em parte iguais? O que acontece com as partes (os pedacinhos da cartolina) quanto mais dobras você fizer no papel?

Nesse sentido o professor ainda pode explorar questionamentos voltados a como poderiam ser expressas essas quantidades (medidas) relacionadas a 
cada parte da tira dividida em partes iguais, podendo explicitar para isso o uso das frações (dos números fracionários).

Sugere-se ainda a associação e a comparação da tira de cartolina e as divisões realizadas com as peças divididas do material na tarefa anterior, na intenção de apresentar as peças e o material e de identificar que assim como se dividiu a tira de cartolina em quatro partes iguais pode-se dividir a peça em quatro partes iguais e assim por diante. Reforçando assim, a fração como um número racional que representa parte(s) de um todo dividido em partes iguais.

Concomitantemente a isso o professor pode evidenciar a representação em Braille dos números fracionários contidos nas peças e proporcionar que o aluno organize o material nas divisórias durante a tarefa, pois se acredita que terá mais facilidade e autonomia posteriores ao representar frações pelas peças e manipulá-las.

\subsection{Comparando frações}

O objetivo desta tarefa é que o aluno realize comparações entre frações, comparando as suas representações, ou seja, comparando o tamanho das peças que representam cada fração. Desta forma, espera-se que o aluno identifique que a fração em que o todo foi dividido em mais partes é a menor das frações dadas, quando se considera somente uma de suas partes. E ainda que quando se compara frações com o mesmo número de divisões do todo, a fração maior será aquela que representa mais partes em relação ao todo. Ou seja, almeja-se ser possível a generalização do conceito de comparação de frações, ao menos com mesmo numerador e denominador, com o material adaptado.

Com o material organizado com a peça que representa o todo no tabuleiro e as outras peças nas divisórias da caixa, sugere-se que a disposição das peças para as comparações de frações seja lado a lado, conforme a figura 2.

O professor pode iniciar a atividade solicitando que o aluno represente com as peças duas frações com numerador um e em seguida questionar: Em 
quantas partes iguais o todo foi dividido em cada uma das frações? Qual dessas frações divide o todo igualmente em mais partes? A peça que representa essa fração é maior ou menor que a peça que representa a outra fração? Então quanto maior a peça em mais partes o todo foi dividido ou o contrário? O que podemos dizer em relação ao tamanho da peça e a fração que a representa? Isso nos ajuda a comparar frações? Como? Qual é a maior fração? Será que isso é sempre válido?

No que se refere a frações que possuem o todo dividido igualmente, o professor pode solicitar que 0 aluno represente duas frações em que 0 denominador é igual e em seguida questionar o aluno: Em quantas partes iguais o todo foi dividido em cada uma das frações? Qual é a maior fração? Quando o todo é igualmente dividido em ambas as frações como podemos saber qual é a maior?

Quanto à comparação de frações com diferentes quantidades de divisões do todo e partes a serem consideradas maiores que um, o professor pode propor a comparação somente pela análise do tamanho da representação das peças, porém para generalizar esta condição faz-se necessário a equivalência de frações para então a comparação ser feita conforme a fração que representar maior parte em relação ao todo igualmente dividido. Uma sugestão seria que após o término da tarefa de equivalência, o professor retome a comparação com este tipo de fração para poder generalizar este conceito.

\subsection{Equivalência de frações}

O objetivo desta tarefa é fazer com que o aluno perceba pela manipulação das peças do material que as frações são equivalentes quando representam a mesma quantidade do todo (representam a mesma parte do todo), embora tenham simbologias e representações diferentes, podemos obter uma fração equivalente por meio de uma representação de fração com peças que dividem de forma diferente $o$ todo em partes iguais, porém encaixam perfeitamente um 
número inteiro de vezes na fração dada (nas peças que se tem). Almeja-se ainda ser possível o aluno identificar que para obter uma fração equivalente basta multiplicar, ou dividir, as divisões do todo e suas partes por um mesmo número (diferente de zero).

Para isto o professor pode propor ao aluno que compare as representações de duas ou três frações que sejam equivalentes, por exemplo, $\frac{1}{2}, \frac{2}{4}$ e $\frac{4}{8}$. E assim questionar o aluno: $O$ que podemos dizer sobre as representações das frações quando as comparamos usando as peças? As frações têm simbologias iguais? E suas representações são iguais? Porém as frações representam a mesma quantidade (parte) do todo?

Para enfatizar que se obtém uma fração equivalente por uma representação de fração que encaixe um número inteiro de vezes na fração dada e para que se perceba que tanto as partes do todo como o número de divisões do todo da fração equivalente são múltiplos, o professor pode perguntar ao aluno: Sabendo que $\frac{1}{2}, \frac{2}{4}$ e $\frac{4}{8}$ são frações equivalentes: Quantas vezes o $\frac{1}{4}$ cabe (ou encaixa) no $\frac{1}{2}$ ? E o $\frac{1}{8}$ cabe (ou encaixa) quantas vezes no $\frac{1}{2}$ ? E no $\frac{2}{4}$ ? Qual é a relação entre o número de partes da fração dada e o número de partes obtidas na sua fração equivalente? E entre o número de divisões do todo na fração dada e na fração obtida pela equivalência?

\subsection{Adicionando e subtraindo frações}

Quanto às operações de adição e subtração de frações com a utilização do material, objetiva-se que o aluno perceba que quando se obtém frações com o mesmo número de divisão do todo em partes iguais pode-se somá-las ou subtraílas de forma intuitiva juntando ou retirando partes do todo dividido igualmente. Ou seja, deseja-se que o aluno perceba que basta operar as quantidades de partes consideradas em relação ao número de divisões do todo que será igual (se manterá). 
Para isso o professor pode propor ao aluno a soma e subtração de frações que possuam o todo dividido em quantidades iguais, pedindo que represente duas frações com mesmo denominador. Por exemplo: $\frac{1}{4}+\frac{2}{4}$ e $\frac{2}{3}-\frac{1}{3}$. Em seguida pode questioná-lo: Em quantas partes o todo foi dividido em cada fração? Devemos juntar/retirar quantas destas partes? Então teremos quantas partes do todo dividido em $n$ (quatro) partes iguais? Então, como podemos somar/subtrair estas duas frações?

Sugere-se que para as operações com frações as peças sejam dispostas lado a lado em mesma fileira conforme a figura 2. E em relação à soma e subtração de frações com o todo dividido em quantidades diferentes em cada fração, é necessário encontrar frações equivalentes, ou seja, que dividam o todo na mesma quantidade de vezes para então somar e subtrair as partes equivalentes consideradas como feito anteriormente. $O$ aluno deverá perceber que tornando a "nova" quantidade em que o todo está dividido para ambas as frações múltiplo de ambas as quantidades da divisão do todo das frações dadas inicialmente, torna-se simples efetuar as operações.

Primeiramente $o$ aluno deve representar as frações com o todo dividido em quantidades diferentes e responder: Será que é possível somar essas frações como estávamos fazendo? Em quantas partes o todo foi dividido em cada uma das frações? Sabemos somar frações que tenham o todo dividido em quantidades diferentes? Se sabemos somar frações que tem o mesmo número de divisões em relação ao todo, como podemos transformar estas frações em frações em que o todo esteja dividido em mesma quantidade? Lembra-se da equivalência de frações? O que fazíamos? Será que é possível encontrar peças que caibam ou encaixem um número inteiro de vezes em ambas as peças que representam as frações dadas? Você consegue estabelecer alguma relação existente entre a quantidade de divisões do todo das frações equivalentes e a quantidade de divisão do todo de cada fração dada?

Caso o aluno realize as equivalências com múltiplos maiores, por mais que o material esteja organizado de peças (representações) menores para as 
maiores, o professor pode explicitar a simplificação de frações, a partir do ato de redividir os todos e reconsiderar as partes.

\section{As limitações identificadas e as possíveis adaptações}

Os apontamentos referentes às limitações e possíveis adaptações tanto do material como dos encaminhamentos das tarefas são oriundos da análise da aplicação das tarefas utilizando o material adaptado em Sala de Recursos Multifuncional II para cegos, trabalhando exclusivamente com uma aluna cega, levando em consideração o rendimento da aluna em manusear o material e também em responder os questionamentos da proposta, visto que o principal objetivo da aplicação foi testar o material. A aplicação foi pensada para ser realizada em seis horas e foi aplicada em dois dias, sendo no segundo dia realizada a aplicação em quatro horas.

A fim de coletar as informações necessárias para compor o relato das atividades propostas e dar embasamento para as análises e reflexões sobre os encaminhamentos da proposta, e principalmente possibilitar a percepção do funcionamento do material, toda a aplicação foi gravada e fotografada a cada manipulação do material pela aluna, como também foi realizada filmagens de pequenos episódios e anotações dos principais resultados.

Quanto ao ato de dobrar a tira em partes iguais na aplicação não houve dificuldades por parte da aluna cega. Porém, verificou-se a dificuldade na percepção dos vincos correspondentes a todas as divisões na tira de papel (que eram feitas na mesma tira). Em nossa avaliação, esse foi um ponto falho do preparo da tarefa, pois acreditamos que a divisão em partes iguais em tiras separadas facilitaria a identificação dos vincos na tarefa inicial, bem como a comparação em relação à peça de madeira (todo), se necessário também substituindo as tiras com vincos equivocados.

Identificamos que o fato da aluna organizar o material enquanto tomava conhecimento das peças e do conceito de fração fez com que obtivesse facilidade 
em manusear e organizar as peças no tabuleiro para realizar as outras tarefas. Dessa forma, pode-se adaptar uma caixa similar a apresentada com outros materiais com o intuito de garantir a significação tátil e a organização para 0 melhor acesso ao conteúdo de frações.

O fato de restringir a aplicação da tarefa à oralidade e a perguntas direcionais para a generalização, fez com que a aplicação realizada em poucas horas se tornasse cansativa. Sugere-se então, que os questionamentos propostos sejam feitos um a um, identificando necessidades de inserção de perguntas mais específicas e direcionais ou de explicações complementares, nesse caso sugerese que a aplicação seja realizada em cerca de dez horas/aulas para assim sistematizar conceitos. Dessa forma, se for desejado obter registros das respostas dadas pelo aluno cego o professor pode transformar os questionamentos apresentados em tarefas impressas em Braille e solicitar que as respostas sejam entregues.

Ressalta-se assim que não se pode exigir dos alunos que em tão pouco tempo e com poucos exemplos cheguem as generalizações propostas. Salientase a necessidade do professor propor diferentes manipulações no material para então sistematizá-las após o aluno identificar alguma regularidade entre os exemplos. Destaca-se em especial a necessidade de maior intervenção quanto a generalização referente a frações equivalentes, a utilização da ideia de múltiplos para obtê-las e consequentemente as operações de operações com frações de quantidades diferentes de divisões do todo que dependem desses conceitos e manipulações para serem resolvidas no material.

Pensando na aplicação e uso deste material realizado em atendimento individual, não se identificou impedimentos para que seja usado em sala regular, em contexto de inclusão. O professor pode inclusive utilizar a proposta deste trabalho também para alunos visuais usando materiais concretos como: frações no pote ou régua de frações concomitantemente com o material adaptado. Além de poder promover o trabalho em grupos com as mesmas orientações e assim 
possibilitar maiores discussões mediante argumentos compartilhados para então generalizar e sistematizar os conceitos e operações de frações.

\section{Considerações finais}

A inclusão de alunos com necessidades especiais, assim como a inclusão de cegos no ensino regular, tem fomentado discussões sobre as potencialidades e dificuldades de práticas educativas inclusivas. Dessa forma, concordamos com Fernandes e Healy (2010, p. 1134), de que a proposta de inclusão "é a que favorece ao aluno incluso integrar-se com seus pares e com o saber". Enquanto que incluir é "oferecer a todos os estudantes uma experiência e um ambiente de aprendizado igualitário e participativo, que corresponde às suas demandas e preferências." (HEHIR, PASCUCCI E PASCUCCI, 2016, p. 3). A inclusão, não prevê, nesse sentido, somente a reestruturação da escola e das práticas pedagógicas do docente, mas também a necessidade de se adaptar e criar materiais e recursos para serem utilizados em sala de aula a fim de promover o acesso de pessoas com necessidades especiais, ou não, ao conhecimento e a experiência.

Mesmo o material adaptado e os encaminhamentos propostos, terem origem e aplicação em um contexto não inclusivo, identificou-se na prática docente com uma aluna cega em Sala de Recurso Multifuncional tipo II, a possibilidade e a necessidade de adaptar um material com significação tátil para o ensino de frações para cegos, bem como os encaminhamentos e tarefas para seu uso, baseados na oralidade.

A experiência vivenciada na construção das tarefas, na adaptação do material e em sua aplicação, foi permeada pelo desafio de buscar compreender as peculiaridades em se ensinar uma pessoa com cegueira. Além de compreender particularidades do ensino de matemática neste contexto, sendo necessário refletir e pesquisar, sobre as possíveis adaptações de recursos e linguagens que aproximam o cego a ter acesso a conceitos a serem ensinados. 
Mediante a análise da aplicação da proposta, percebeu-se que a forma da organização e estruturação do material, permitiu que a aluna cega tivesse contato com os conceitos de frações pela percepção do tato, sem ter problemas com falta de organização, perca de peças e dificuldade em identificá-las. Da forma como a proposta foi aplicada e está sugerida, considera-se que permite explorar o conceito de fração, comparar duas frações e realizar a equivalência e as operações de adição e subtração de frações, atestando potencialidade nas tarefas propostas para a utilização do material no ensino de matemática a cegos.

Nesse contexto, avalia-se que o material e sua proposta de utilização, aqui brevemente descrita, bem como as contribuições quanto a modificações e alterações que foram identificadas pela aplicação e que visam o aperfeiçoamento do material e da proposta, permitam outras adaptações e reuso do material e da proposta por outros profissionais, a fim de promover o ensino de frações a alunos cegos e também videntes mediante, sua possibilidade de aplicação em contexto de inclusão.

\section{Referências}

BRASIL. Secretaria de Educação Fundamental. Parâmetros curriculares nacionais: matemática/ Secretaria de Educação Fundamental. - Brasília: MEC/SEF, 1997.

Disponível em: <http://portal.mec.gov.br/seb/arquivos/pdf/livro03.pdf>. Acesso em: 28 fev. 2014.

. Ministério da Educação e Cultura. Portaria MEC no 1.010, de 10 de maio de 2006. Brasil: 2006. Disponível em: < http://laramara.org.br/uploads/arquivos/legislacao/portaria-mec-n-1010-2006Soroban.pdf>. Acesso em: 27 abr. 2014.

COSTA, Fabio Meneses. Concepções e competências de Professores Especialistas em Matemática em relação ao conceito de Frações em seus diferentes significados. 2011, 176 p. Dissertação (Mestrado em Ensino de Matemática)- Pontifícia Universidade Católica de São Paulo- PUC/SP, São Paulo, 2011.

FERNANDES, Solange Hassan Ahmad Ali; HEALY, Lulu. A Inclusão de Alunos Cegos nas Aulas de Matemática: explorando Área, Perímetro e Volume através do tato. Revista Bolema, Rio Claro: v. 23, no 37, p. 1111 à 1135, dez. 2010. 
Relações entre o "visto" e o "sabido": as representações de formas

tridimensionales feitas por alunos cegos. Unión Revista Iberoamericana de Educación Matemática, ํo 26, p. 137 à 151, jun. 2011.

HEHIR,T.; PASCUCCI, S.; PASCUCCI, C. Os Benefícios da Educação Inclusiva para Estudantes com e sem Deficiência. Org. Abt associates e Instituto Alana. São Paulo, 2016. $34 \mathrm{p}$.

MACHADO, Cacilda Tenório Oliveira. Concepções Epistemológicas e Experiências de Professores de Matemática com Números Fracionários: as Implicações em suas Práticas na 5a série do Ensino Fundamental. 2007, 132 p. Dissertação (Mestrado em Ensino das Ciências)- Universidade Federal Rural de Pernambuco, Recife, 2007.

MALASPINA, Maria da Conceição de Oliveira. O inicio do Ensino de Fração: Uma intervenção com alunos de $2^{\mathrm{a}}$ série do Ensino Fundamental. 2007, 184 p.

Dissertação (Mestrado em Educação Matemática)- Pontifícia Universidade Católica de São Paulo- PUC/SP, São Paulo, 2007.

MERLINI, Vera Lucia. O conceito de fração em seus diferentes significados: um estudo diagnóstico com alunos de 5a e 6⿳亠丷厂 séries do Ensino Fundamental. 2005, 238 p. Dissertação (Mestrado em Educação Matemática)- Pontifícia Universidade Católica de São Paulo, São Paulo, 2005.

MORAIS, Vanessa da Silva Chaves de. Uma sequência de atividades para o estudo de operações com frações com uso de materiais manipuláveis. 2012, 113 p. Dissertação (Mestrado Profissionalizante em Ensino de Física e de Matemática)- Centro Universitário Franciscano- UNIFRA, Santa Maria, Rio Grande do Sul, 2012.

PARANÁ. Secretaria de Estado da Educação do Paraná. Diretrizes Curriculares da Educação Básica de Matemática. Paraná: 2008. Disponível em:

$<$ http://www.nre.seed.pr.gov.br/irati/arquivos/File/matematica.pdf>. Acesso em: 28 fev. 2014.

PELISSARO, Simone. Ensino de frações: novas abordagens. 2011, 34 p. Trabalho de Conclusão de Curso (Especialização em Matemática, Mídias e Didáticas)- Universidade Federal do Rio Grande do Sul, Vila Flores, 2011.

POLESE, Felipe Oneda. Análise de uma proposta construtivista de ensino de frações por meio da resolução de problemas. 2011, 104 p. Dissertação (Mestrado em Educação em Ciências e Matemática)- Pontifícia Universidade Católica do Rio Grande do Sul, Porto Alegre, 2011.

SILVA, Angélica da Fontoura Garcia. 0 desafio do desenvolvimento profissional docente: análise da formação continuada de um grupo de professores das séries iniciais do Ensino Fundamental, tendo como objeto de discussão o processo de Ensino e a Aprendizagem das Frações. 2007, 308 p. Tese (Doutorado em Educação Matemática)- Pontifícia Universidade Católica de São Paulo, São Paulo, 2007. 
SILVA, Adegundes Maciel da. Investigando a concepção de frações de alunos nas séries finais do Ensino Fundamental e do Ensino Médio. 2006, 104 p. Dissertação (Mestrado em Ensino das Ciências)- Universidade Federal Rural de Pernambuco, Recife, 2006.

SILVA, Maria José Ferreira da. Sobre a introdução do conceito de número fracionário. 1997, 245 p. Dissertação (Mestrado em Ensino da Matemática)- Pontifícia Universidade Católica de São Paulo, São Paulo, 1997.

VASCONCELOS, Isabel Cristina Peregrina. Números Fracionários: A construção dos diferentes significados por alunos de $4^{\mathrm{a}}$ à $8^{\mathrm{a}}$ séries de uma escola do Ensino Fundamental. 2007, 103 p. Dissertação (Mestrado em Educação)- Universidade Federal do Rio grande do Sul, Porto Alegre, 2007. 